\title{
El Quiasma de la sublimación: aproximaciones interdisciplinares
}

\author{
The Chiasm of Sublimation: Interdisciplinary Approximations
}

\author{
Niklas Bornhauser Neuber ${ }^{1}$, Diego Ochoa ${ }^{2}$ \\ ${ }^{1}$ Universidad Andrés Bello, Escuela de Psicología, Santiago, Chile. \\ Correo electrónico: nbornhauser@unab.cl \\ ${ }^{2}$ Universidad Complutense de Madrid, Estudiante de Máster en Psicoanálisis y Filosofía de la Cultura, \\ Madrid, España. Correo electrónico: diego_ochoa_h@hotmail.com
}

El concepto de sublimación, en lugar de inscribirse en un territorio discursivo único y privativo, atraviesa diferentes prácticas disciplinares, entre ellas, la literatura y el psicoanálisis. A partir de la lectura de ciertos fragmentos de Goethe y de Freud se rastrea el concepto de sublimación, interrogándose por las relaciones de reciprocidad entre ambos.

Palabras clave: sublimación, Goethe, Freud, límite, lenguaje.

The concept of sublimation, rather than enrolling itself in a unique and exclusive discursive territory, traverses different disciplinary practices, including literature and psychoanalysis. Hence, this study traces the concept of sublimation through the lecture of certain passages of Goethe and Freud, questioning the relationships of reciprocity between them.

Key words: sublimation, Goethe, Freud, border, language.

Ni lo próximo ni lo lejano apaciguan el corazón profundamente turbado.

(Goethe, Fausto, Prólogo)

\section{INTRODUCCIÓN}

El concepto de sublimación, en la actualidad, no es solamente un concepto crucial en y para el psicoanálisis (Gay 1992), sino que de él se desprende una serie de consecuencias y derivaciones relevantes para el debate contemporáneo en general (De Berg 2004). Según Hacker (1972), sus principales implicaciones, más allá de la 
teoría y práctica psicoanalítica propiamente tales, repercuten en las ciencias literarias y los estudios culturales. Lejos de reducirse a ser únicamente un término psicoanalítico acotado y altamente especializado, la noción de sublimación, en la medida en que atraviesa y evoca conceptos procedentes de diferentes ámbitos disciplinares, sugiere una serie de relaciones transdisciplinares entre sus respectivos dominios discursivos (Goeppert y Goeppert 1981). La justa consideración del concepto de sublimación y de sus alcances, por ende, invitan a un abordaje plural, abierto y desprejuiciado en el cual Freud constituye un referente entre otros. En tanto un tipo particular de destino pulsional, que involucra y pone en relación tanto a la esfera individual como a las exigencias y los valores culturales, el concepto de sublimación se ofrece como un punto de discusión poliestratificado y sobredeterminado, en el cual convergen tramas argumentativas diversas.

Ha sido subrayado que el concepto de sublimación no es un aporte original ni privativo del psicoanálisis y que su genealogía nos envía, entre otros, a la obra de Goethe (Goebel 2009), Schopenhauer (Becker 1972) y Nietzsche (Gasser 1997), en quienes se encuentra ya sea una idea delimitada de ésta o, al menos, ciertos precursores relevantes para su ulterior configuración conceptual. Entre los pensadores mencionados, destaca el nombre de Johann Wolfgang von Goethe, no solamente por ser el primero - en el sentido cronológico - de esta lista, sino, en primer lugar, por su documentada incidencia tanto en la escritura como en el pensamiento de Freud y, en segundo, por los efectos que pueda tener el psicoanálisis freudiano para la lectura de Goethe, no en el sentido de la psicobiografía, sino del diálogo horizontal y fecundo entre dos prácticas escriturales. En concreto, interesa discutir el lugar y las posibles relaciones de significación a ser establecidas a partir del concepto de sublimación mediante una lectura simultánea de Goethe y Freud, que considere a ambos como referentes sin presuponer la anterioridad o prevalencia, ya sea cronológica o lógica, de uno sobre el otro. En ese sentido, se espera contornear el concepto de sublimación prescindiendo de establecer relaciones causales o deterministas, apostando a una lectura desprejuiciada y productiva, capaz de recortar el concepto sobre su correspondiente fondo intertextual.

Por ende, el presente trabajo propone problematizar el concepto de sublimación por dos vías diferentes, pero no excluyentes: una, que podríamos llamar arqueológica, de rastreo conceptual, que renuncia a toda pretensión de escudriñar o establecer, síntesis mediante, la unidad homogénea e invariable, sino que apunta a la proliferación de las múltiples instancias de la diferencia, la pluralidad y la discontinuidad. Dicha arqueología no supone ni requiere la existencia de un sujeto-soporte fundante, capaz de avalar el calmo despliegue de una cronología lineal y continua al modo de una secuencia progresiva de los conocimientos materiales orientada hacia una objetividad incorruptible cada vez mayor. La arqueología apuesta a multiplicar las rupturas y amplificar las fisuras, sortear las Robinsonadas y las miradas retrospectivas, en suma: renunciar a la plétora del sentido. De este modo, el interés recaerá, de modo particular, en las discontinuidades y transformaciones del concepto de sublimación, los cruces y topes entre Freud y Goethe, los tránsitos y las incompatibilidades entre ellos. Por el otro lado, se proyecta una vía genealógica, que apuesta a interrogar la idea de sublimación como una maquinaria, que pone a trabajar a diferentas ideas, juntándolas u oponiéndolas entre sí con el objetivo de conformar un dispositivo reflexivo que permita desanquilosar ciertas relaciones de significación heredadas y fosilizadas con el propósito de pensar(las) de otro modo. Lo anterior supone trabajar 
no sólo a partir de las diferencias (históricas, semánticas, relacionales, etc.) que se puedan encontrar en la construcción lógica de las concepciones convocadas, sino, asimismo, exige considerarlos como genuinos mecanismos, es decir, pensarlos desde y como los movimientos y desplazamiento implicados en ellos.

La pregunta que guía este trabajo, a saber, en qué medida y hasta qué punto el concepto de sublimación puede servir de puente de conexión o de plataforma giratoria, evoca la figura de un quiasma ${ }^{1}$, es decir, de un organismo compuesto, cuyo entrecruzamiento lo hace funcionar a partir de la unión y la desunión. Nuestra hipótesis es que el concepto de sublimación, tanto a partir de su raigambre plural como de los efectos multiplicadores de la dispersión de sus implicancias, puede constituirse en un punto de partida para pensar ciertas relaciones entre el psicoanálisis, la literatura, el arte y la estética. Los textos de J. W. von Goethe y de S. Freud, que traspasan justamente estos ámbitos, conforman, en su diferencia, un mosaico inaugural, situado en el campo de la cultura. Goethe, quien ha sido calificado como "el último verdadero hombre universal que caminó sobre la tierra”, nos heredó una obra variada y diversa, que abarca géneros como la novela, la poesía lírica, el drama y los tratados científicos, dejando una huella imperecedera en escritores, compositores, pensadores y artistas. A su vez, las frecuentes incursiones freudianas en la literatura -su lectura de la Gradiva de W. Jensen, las reiteradas alusiones a Goethe, Schiller y Heine, su escrito sobre el creador literario y el fantaseo y el análisis de Dostoievski, para nombrar solamente a algunos- y la creación artística en general -pensemos en sus ensayos sobre el Moisés de Miguel Ángel y la obra de Leonardo da Vinci -inscriben la reflexión psicoanalítica en un territorio compuesto y misceláneo, en el cual dialoga con las ciencias literarias y las bellas artes.

La pregunta por la sublimación se abordará a través de un itinerario, en principio histórico, cuyo principal interés reside en ir marcando las diferencias que se dan a partir de la introducción de concepciones nuevas y sus relaciones con otros mecanismos que se verán implicados secundariamente. Dicha metodología está basada en el supuesto de que el psicoanálisis, desde sus orígenes, es una práctica híbrida, plural y heterogénea, en cuya constante reformulación converge un número de prácticas diversas y desemejantes, que se fecundan y repelen recíprocamente. Así, no se apunta a formular definiciones conceptuales definitivas y concluyentes, sino que se persigue la apertura de nuevos caminos del pensar, menos recorridos y más silvestres, mediante los cuales las preguntas inicialmente esbozadas puedan seguir replanteándose, convirtiendo sus dudas y ambigüedades conceptuales en fortalezas y motivo de una futura discusión.

\section{GOETHE À FREUD}

La incidencia del pensamiento freudiano en el debate contemporáneo ha sido estudiada desde sus repercusiones más generales e inespecíficas (Ricoeur 1969), así como en cuanto a sus resonancias más acotadas en el campo de la psicología (Braunstein 1975; Jahoda 2002), la filosofía (Habermas 1968; Bachelard 1948) y las ciencias

Podemos constar aquí ciertas analogías con la formación del pliegue en Merleau-Ponty. El ser-para-sí y el ser-paraotro pasan a constituir la figura del quiasma o de la reversibilidad, que Merleau-Ponty (1945) describe como el dedo del guante que se vuelve al revés, situación en la cual no es necesario ver los dos lados del guante, ya que una parte se ve y otra se toca. 
literarias (Assoun 1996; Starobinski 1970). Sin embargo, la abundancia de estudios dedicados a retratar estas influencias contrasta con la relativa escasez de investigaciones sobre el influjo de la cultura de lengua alemana en el surgimiento del psicoanálisis.

Una de las pocas excepciones la constituye el trabajo de Ernest Jones (1953, 1955, 1957), que en su extensa biografía de Sigmund Freud describe detalladamente el influjo de la cultura alemana en la conformación del psicoanálisis freudiano especificando las incursiones de Freud en la literatura y sus posibles efectos en su pensamiento. Jones documenta cómo la educación humanista de Freud lo familiarizó con la obra de Sófocles, Shakespeare, Cervantes, Darwin y muchos otros. Destaca, al interior de un conjunto de pensadores clásicos, la figura y obra de Johann Wolfgang von Goethe y ello por varios motivos. Si bien hoy en día sabemos (Zaretsky 2006) que la biografía de Jones contiene numerosas imprecisiones históricas y que retrata un Freud idealizado, enaltecido, creador solitario de un psicoanálisis científico, posee el mérito de señalar la centralidad de la relación Goethe-Freud. Otros biógrafos de Freud, principalmente Ronald Clark (1980) y Peter Gay (1988), sin detenerse en realizar un análisis pormenorizado, han aportado una serie de razones por las cuales dicha relación puede resultar de interés para un estudio transdisciplinar.

En primer lugar, por razones que podríamos llamar epocales. Admirar -o incluso imitar- a Goethe, dada la relevancia de éste para la discusión académica durante la segunda mitad del siglo XIX y a comienzos del siglo XX era algo bastante esperable para un intelectual europeo. Hanns Sachs confirma la centralidad de Goethe al afirmar que: "Para todos aquellos que nacieron y fueron educados en el círculo cultural alemán durante el siglo XIX, había un tema de conversación inagotable, imperecedero: Goethe. Su vida y su obra por ende jugaban un rol nada desdeñable en nuestros diálogos”2 (Sachs 1932: 96, trad. nuestra). Arnold Bergstraesser en su ensayo "Goethe und unsere Zeit" describe un cambio en la recepción de Goethe, acontecido en el paso del siglo XIX al XX. Dice: "Se han vuelto visibles las dimensiones profundas de su esencia y de su mérito poético y científico"33 (Bergstraesser 1950: 77, trad. nuestra). Es decir, serían justamente las dimensiones "profundas" de su esencia y de sus descubrimientos poéticos y científicos los que se habrían vuelto visibles a partir del siglo XX. Cabe preguntar cuál es el rol que habría jugado el psicoanálisis, también conocido como "psicología de las profundidades" (Tiefenpsychologie) en dicho desocultamiento. André Suarès, quien no era precisamente un amante de la cultura alemana, no solamente es el autor del libro Goethe. Le Grand Européen (1932), sino que incluso redactó un artículo titulado "Goethe - 1'Universel”. De acuerdo a Suarès: "Goethe es el más grande de los europeos [...] No hay salvación para Europa que no sea en el espíritu de Goethe. Pero no es posible que este espíritu se apague, porque es el espíritu de la propia Europa y Europa no sería más que una palabra vacía sin él”4 (Cit. en Mommsen 1999: 37, trad. nuestra). El mismo Freud, en

\footnotetext{
"Für alle jene, die im neunzehnten Jahrhundert im deutschen Kulturkreis geboren und erzogen wurden, gab es ein unerschöpfliches, unversiegbares Gesprächsthema: Goethe. Sein Leben und seine Werke spielten daher keine geringe Rolle in unseren Unterhaltungen".

3 "Es sind Tiefendimensionen seines Wesens und seiner dichterischen und wissenschaftlichen Leistung sichtbar geworden”.

4 'Goethe est le plus grand des Européens; [...] Il n'y a pas de salut pour l'Europe que dans l'esprit de Goethe. Mais il n'est pas possible que cet ésprit s'éteigne, puisqu'il est celui de l'Europe même, et que l'Europe ne serait qu'un mot vide sans lui”.
} 
una conferencia escrita con motivo de la entrega del premio Goethe en 1930, llama a Goethe "la figura (Gestalt) del gran (Hombre) Universal (Universellen)" (292). La lista de pensadores que subrayan la relevancia de Goethe para el pensamiento de su época es impresionante y, en todo caso, demasiado extensa para ser comentada de modo pormenorizado: Romain Rolland, André Gide, Paul Valéry, Gabriela Mistral, Benedetto Croce, Georg Lukács, etc. Walter Schönau concluye que el elevado número de referencias literales o aproximadas a Goethe, en general, y al Faust, en particular, no resultan sorprendentes si se considera el lugar y la relevancia de dicha obra en el Bildungsleben alemán.

Freud, quien no era ninguna excepción a esta regla general, poseía tanto la edición de Cotta de Goethes sämtlichen Werken del año 1860, así como la llamada Sophienausgabe, editada a partir de 1887. Según Ernest Jones (1955), Freud estaba familiarizado con la obra de Goethe desde su temprana niñez. Rapaport (1970) confirma esta temprana inclinación o preferencia por Goethe.

Segundo, por razones investigativas o incluso vocacionales, relacionadas con la pulsión epistemofílica o la voluntad de saber: según cuenta el propio Freud en su Presentación autobiográfica, "la lectura en una conferencia popular (por el profesor Carl Brühl) del hermoso ensayo de Goethe "Die Natur", que escuché poco antes de mi examen final de bachillerato, me decidió a inscribirme en medicina" (Freud 1925: 8-9). El ensayo Fragment über die Natur también figura en uno de los sueños relatados por Freud en Die Traumdeutung (1900 [1899]), cuando se refiere a él ya sea como "el bien conocido ensayo de Goethe "Naturaleza"" (1900: 644) o como "aquel hermoso ensayo de Goethe” (645). Actualmente se sabe que dicha convicción es un malentenido, ya que el texto original, aparecido anónimamente en 1780, y del cual existe una versión revisada y modificada por parte de Goethe, es atribuido a Georg Christoph Tobler.

Tercero, por razones que guardan relación con los escritos freudianos y sus referencias directas o indirectas a la obra de Goethe, entre los textos que tratan directamente sobre el tema habría que destacar, principalmente, "Un recuerdo de infancia” en Poesía y verdad (1917) y, por supuesto, la conferencia Premio Goethe (1930). En términos generales, las referencias a Goethe son constantes a lo largo de toda la obra freudiana: desde las cartas a Fliess, escritas entre 1892 y 1899, hasta Análisis terminable e interminable, publicada en 1937. Probablemente no haya ningún otro autor citado con tanta frecuencia como Goethe: sólo en el intercambio epistolar con Fliess aparece mencionado más de veinte veces. ${ }^{5}$

Dicho dato es relevante por dos motivos: primero, por la especial relación de Freud con Fliess, quien era su amigo cercano y confidente, con quien compartía sus ideas más íntimas y germinales; segundo, porque las cartas de Freud han sido calificadas, ya sea como obra paralela o complementaria, suerte de comentario constante sobre la obra escrita oficial. Incluso ha sido argumentado que Freud y su obra no pueden ser comprendidos sin leer sus cartas (Falzeder 2007).

Freud era un escritor prolífico: redactó más de 20000 cartas en vida. Destaca en ellas su seguridad estilística, su dominio del lenguaje, su humor, su capacidad de observación, pero también sus debilidades. Según Fichtner, "hasta la carta más

En el Manuscrito N, anexado a la carta 64, fechada el 31 de mayo de 1897, Freud escribe: "El mecanismo de la poesía (creación literaria) es el mismo que el de las fantasías histéricas. Goethe reúne en Werther algo vivenciado, su amor por Lotte Kästner, y algo oído, el destino del joven Jerusalem, que se suicidó” (Freud, 1887: 297). 
pequeña e irrelevante lleva el sello de su lenguaje y de su pensamiento” (1989: 806) y Walter Jens, a propósito de la publicación de una primera selección de las cartas de Freud en 1960 escribe "nuestro país ha ganado un escritor importante, finalmente descubierto"6 (Cit. en Fichter 1989: 804, trad. nuestra). En resumen, las cartas de Freud son una fuente histórica plural, compleja y única, ya que no solamente aportan valioso material biográfico y conforman una inagotable fuente para la construcción de la historia del llamado movimiento psicoanalítico, sino porque en ellas numerosas ideas aparecen por primera vez, transparentando el contexto en el que surgieron, aportando a la escritura de la Ideengeschichte.

Las referencias al Fausto, en general, y a Mefistófeles, en particular, son numerosas: "Lo mejor que alcanzas a saber/ No puedes decirlo a los muchachos" (1900: 160) incluso ha sido calificada por E. Strachey como "una de las citas favoritas de Freud" (1900: 160, n. 7), que por primera vez aparece en la carta a Fliess del 3 de diciembre de 1897 y por última al final de su vida, cuando en el texto escrito con motivos de la entrega del premio Goethe la aplicaría al propio poeta alemán. De particular interés también le resultaba la parte I, escena 3 de Faust, en la que Mefistófeles exclama: "De la tierra, del aire y de las aguas/ se desprenden miles de gérmenes/ en lo seco y lo húmedo, lo cálido y lo frío,/ y si no me hubiera reservado las llamas,/ nada tendría propiamente para mí" (Goethe cit. en Freud 1900: 78). Freud se refiere a este pasaje en La interpretación de los sueños (1900 [1899]), comparando a los gérmenes de la vida, de los cuales se queja Mefistófeles, con los estímulos, procedentes de las más diversas fuentes, que perturban el dormir. En El malestar en la cultura (1930 [1929]), Freud a partir del mismo pasaje sugiere cierta analogía entre "el principio del mal con la pulsión de destrucción en el Mefistófeles de Goethe” (1930: 116). Más allá de los usos y la diversidad de las interpretaciones, lo que se repite es la constante referencia, parcial o global, a la obra de Goethe. Esta referencia, de acuerdo a lo adelantado, es de carácter diverso, dependiendo del contexto y del momento en el pensamiento de Freud. En términos generales, la presencia de Goethe en la obra freudiana es incesante, trátese de forjar un modelo general para las formaciones del inconsciente, entre las cuales se encuentran el síntoma neurótico, el sueño, el lapsus y el chiste, o de contribuir a una reflexión especial sobre la escritura.

\section{CAMINOS Y DESCARRÍOS DE LA SUBLIMACIÓN}

A pesar de hacer frecuentes y reiteradas alusiones al concepto de sublimación, Freud no elaboró una teoría unitaria de la sublimación ni logró explicar de modo consistente y pormenorizado cómo operaría en tanto mecanismo u operación (Mertens y Waldvogel 2000). En otras palabras, no existe algo así como una teoría única o concluyente de la sublimación en psicoanálisis (Laplanche y Pontalis 1967), ni contamos con textos canónicos o destacados en los cuales se resuelvan, de modo definitivo, las preguntas relacionadas a su estatuto, sus mecanismos y alcances.

De entrada, llama la atención que Freud utilice una palabra de origen latino, Sublimierung, prescindiendo de emplear otros términos disponibles tales como Aufhebung, Vergeistigung o Schöpfung. La traductora de Freud, Johanna Borek,

"Unser Land ist um einen bedeutenden, endlich entdeckten Schriftsteller reicher geworden". 
al respecto observa en una entrevista publicada en Der Standard: "Freud emplea dos niveles de conceptualización; una alemana y una latina. De modo enteramente consciente elige como lenguaje de su terminología a ambas: libido y sublimación, por un lado, pulsión, represión, interpretación, por el otro. Emplea conceptos alemanes con las cuales se tornan posibles connotaciones del todo diferentes. Como un escritor deja trabajar el lenguaje por sí solo, formula de un modo que sus textos no son reducibles a un enunciado. Por lo anterior Freud es tan difícil de traducir y las viejas traducciones son completamente insuficientes -pero ellas han marcado la recepción de Freud en otros países” (Borek 2010: 14, trad. nuestra).

La partícula sub, en el caso de Sublimierung, no indica solamente una relación de inferioridad o sumisión, sino que se vincula con super, sugiriendo la idea de desplazamiento hacia lo alto y elevado. Sublimis significa, según el Dictionnaire étymologique de la langue latine de A. Ernout y A. Meillet (1979), que "se va elevando, que se mantiene en el aire”. Deriva del adjetivo limus o limis, oblicuo, es decir, "que mira de costado o de través, que sube en línea oblicua o en pendiente”, y, según Festus, asimismo remite a limen, límite, implicando la idea de atravesar un umbral, incluso de transgredir (Festus en Cohn \& Miles 1977). Procedente de la alquimia (Jung 1977), la operación de sublimación designa un modo de metamorfosis que implica el paso del estado sólido al estado gaseoso, omitiendo pasar por la fase líquida intermedia. El cuerpo sujeto a dicho proceso conserva sus propiedades intactas, por lo que clásicamente es entendida como un procedimiento de purificación, que apunta a liberar al cuerpo en cuestión de sus partes heterogéneas, sobrantes o superfluas.

Si de establecer los orígenes del término se trata, el primer antecedente lo constituye el Simposio de Platón, en el cual la idea de la sublimación se expresa de modo ejemplar (Pechriggl 2006). No obstante, es razonable suponer que Freud se haya encontrado con este concepto en Aus meinem Leben. Dichtung und Wahrheit de J. W. Goethe, un escrito de carácter autobiográfico, redactado entre 1808 y 1831, que narra los acontecimientos ocurridos entre 1749 y 1775. En una conversación con Johann Peter Eckermann, el 30 de marzo de 1831, Goethe le comentó a éste que se trataba de "puros (lauter) resultados de su vida" y que el nombre se debía a que el libro a través de tendencias más enaltecidas (höher) se eleva (sich erhebt) desde la región de una realidad más baja o inferior (niedern) (Biedermann 1010: 358, trad. nuestra). ${ }^{7}$ La metáfora espacial, que se recogería con posterioridad en la idea de sublimación, está presente desde un inicio.

Ya en la segunda parte de Dichtung und Wahrheit, dice: "Y así comenzó aquella tendencia de la cual no podría apartarme a lo largo de toda mi vida, a saber, la de transformar en una imagen o un poema lo que me agradaba o torturaba, u ocupaba de algún otro modo, y de resolver, con tal de corregir mis conceptos/ideas de las cosas externas, así como para calmarme internamente. Este don probablemente a nadie le era más necesario que a mí, ya que mi naturaleza me arrojaba una y otra vez de un extremo al otro. Por ende, todo lo que ha sido conocido de mí no son sino fragmentos de una gran confesión y este librito no es otra cosa que un intento audaz de contribuir a su completud (Goethe 1948: 283, trad. nuestra).”"

"Es sind lauter Resultate meines Lebens [...] Ich dächte, es steckten darin einige Symbole des Menschenlebens. Ich nannte das Buch Wahrheit und Dichtung, weil es sich durch höhere Tendenzen aus der Region einer niedern Realität erhebt".

8 "Und so begann diejenige Richtung, von der ich mein ganzes Leben über nicht abweichen konnte, nämlich dasjenige 
O sea, aquello que alegraba o martirizaba, en términos generales, ocupaba a Goethe, se transformaba en un cuadro, un poema, con tal de corregir las representaciones conceptuales respecto de las cosas exteriores o de calmar el psiquismo del poeta alemán. Incluso llega a calificar su creación como "una gran confesión".

La conocida metáfora del balón, que evoca la fórmula de la sublimación, se encuentra en el siguiente pasaje, en el cual retornan el placer y el dolor como fuentes de la creación: "La verdadera poesía se anuncia por el hecho de que ella, en tanto evangelio secular, a través de la alegría interior, la satisfacción exterior, sabe librarnos de las cargas terrenales que nos oprimen. Como un globo nos eleva junto al lastre desplegado (adherido), hacia regiones más altas y despliega, ante nosotros, a vista de pájaro, los enredados derroteros del mundo. Tanto las obras más alegres como las más serias comparten un mismo propósito: moderar tanto el placer como el dolor mediante una ingeniosa y feliz representación” (580, trad. nuestra). ${ }^{9} \mathrm{La}$ poesía, por consiguiente, se caracteriza por su capacidad de librar al poeta de las cargas mundanas que amenazan con aplastarlo bajo su peso. El contraste entre las "regiones más elevadas" y el triste y profano mundo de las privaciones mundanas, más vulgares, más comunes y más bajas, nuevamente es reiterado.

La idea de la transformación del sufrimiento en creación artística se repite en Torcuato Tasso: "Y cuando el hombre en su dolor se calla, me ha dado un dios que exprese cuánto sufro" (1790: 139, trad. nuestra). ${ }^{10}$ Contribuyendo a la formación del ideal del científico-artista, cuyo nombre propio es la sublimación, Goethe supera el uso meramente metafórico del término para caracterizar la creación poética, afirmando que los estados del alma y los sentimientos no pueden relacionarse sin más con su natural originario, sino que tienen que ser trabajados, preparados, elaborados y sublimados (erarbeitet, zubereitet, sublimiert).

\section{FREUD: DESPLAZAMIENTOS Y TRÁNSITOS}

La primera aparición ${ }^{11}$ del término Sublimierung se ubica en una carta dirigida a Wilhelm Fliess, escrita el 2 de mayo de 1897, en la que Freud sostiene que "las fantasías provienen de lo oído, entendido con posterioridad, y desde luego son genuinas en todo su material. Son edificios protectores, sublimaciones de los hechos,

was mich erfreute oder quälte, oder sonst beschäftigte, in ein Bild, ein Gedicht zu verwandeln und darüber mit mir selbst abzuschließen, um sowohl meine Begriffe von den äußeren Dingen zu berichtigen, als mich im Innern deshalb zu beruhigen. Die Gabe hierzu war wohl niemand nötiger als mir, den seine Natur immerfort aus einem Extreme in das andere warf. Alles, was daher von mir bekannt geworden, sind nur Bruchstücke einer großen Konfession, welche vollständig zu machen dieses Büchlein ein gewagter Versuch ist".

9 "Die wahre Poesie kündigt sich dadurch an, dass sie, als ein weltliches Evangelium, durch innere Heiterkeit, durch äußeres Behagen, uns von den irdischen Lasten zu befreien weiß, die auf uns drücken. Wie ein Luftballon hebt sie uns mit dem Ballast, der uns anhängt, in höhere Regionen und lässt die verwirrten Irrgänge der Erde in Vogelperspektive vor uns entwickelt da liegen. Die muntersten wie die ernsteren Werke haben den gleichen Zweck, durch eine glückliche geistreiche Darstellung so Lust als Schmerz zu mäßigen”.

10 "Und wenn der Mensch in seiner Qual verstummt,/ Gab mir ein Gott, zu sagen, wie ich leide".

11 El calificativo de "lo primero" no ha de ser entendido como la evocación de un origen primordial y privilegiado, punto de partida irreductible de todo devenir ulterior, sino, más bien, como un antecedente establecido a posteriori, nachträglich, y cuya significación en ningún caso lo precede, sino que está por establecerse -y disolversehistóricamente. 
embellecimientos de ellos, y al mismo tiempo sirven al autodescargo" (Freud 1987: I, 288). No obstante, la carta prosigue por otras vías analíticas, sin detenerse a examinar o desarrollar esta primera idea de sublimación. Sería en el llamado "caso Dora”, en el que Freud, a propósito de las perversiones, hace referencia a la posibilidad que ciertos "gérmenes" de la disposición sexual infantil pueden experimentar un giro hacia metas "más elevadas", diferente de las sexuales y que puedan ser asociadas con valores culturales. Dice literalmente en el texto citado: "Las perversiones [...] son desarrollos de gérmenes, contenidos todos ellos en la disposición sexual indiferenciada del niño, cuya sofocación o cuya vuelta (Wendung) hacia metas más elevadas, asexuales -su sublimación-, están destinadas a proporcionar la fuerza motriz de un buen número de nuestros logros culturales" (1905 [1901]: 45). En el mismo escrito, Freud relaciona sublimación con transferencia, a saber, el proceso en virtud del cual los deseos inconscientes se actualizan sobre ciertos objetos, general pero no exclusivamente dentro de la relación analítica, sosteniendo que tiene que ver con reediciones o reimpresiones de figuras anteriores situadas, ahora, en un tiempo presente. Pero, advierte, hay transferencias que "proceden con más arte" (1905 [1901]: 101), ya que han sido moderadas en su contenido.

Por lo tanto, son dos las características que en este primer momento se acentúan respecto a la sublimación: por un lado, la desexualización, la desviación, la posibilidad de cambiar la meta original por otra, "más elevada", y, por el otro, la posibilidad de transitar entre tiempos diferentes: desde la sexualidad infantil y sus modos de satisfacción, asociados al objeto de amor primero, a una actualidad que ha devenido por entero diversa en su meta, pero cuya fuente continúa siendo la pulsión. Estas reflexiones en torno a la sublimación pueden ser consideradas una antesala de las ideas que Freud formulará más acabadamente cuatro años después, en Tres ensayos de teoría sexual (1905), donde se definirá la sublimación como "una desviación de las fuerzas pulsionales de sus metas, y su orientación hacia metas nuevas” (1905:162).

Concretamente en el libro recién citado, escrito en el cual hay una serie de alusiones al problema de la sublimación, Freud, a propósito de las fijaciones de metas sexuales provisionales, escribe: "Empero, [la curiosidad sexual] puede ser desviada ("sublimada") en el ámbito del arte, si uno puede apartar su interés de los genitales para dirigirlo a la forma del cuerpo como un todo [...] Y esto les da aun la posibilidad de dirigir cierto monto de su libido a metas artísticas más elevadas” (1905: 142). En el mismo texto encontramos la referencia al "Prólogo en el teatro" del Fausto de Goethe, cuando dice: "En la sexualidad, lo más sublime y lo más nefando aparecen por doquier en íntima dependencia ("Desde el cielo, pasando por el mundo, hasta el infierno")" (1905: 147). Justamente a propósito de la presencia de Goethe en el texto freudiano, Robert Pfaller ha demostrado que al concepto de sublimación, a diferencia de otros conceptos centrales para el psicoanálisis, desde sus inicios le adhiere algo prestado, adquirido, “etwas Übernommenes” (2009: 623), que lo inscribe inequívocamente en una tradición del pensar que precede y supera el aporte freudiano. Concretamente, Freud en los Tres Ensayos afirma que: "Los historiadores de la cultura parecen contestes (scheinen einig) en suponer que mediante esta desviación de las fuerzas pulsionales sexuales de sus metas, y su orientación hacia metas más nuevas (un proceso que merece el nombre de sublimación), se adquieren poderosos componentes para todos los logros culturales” (1905: 161). La supuesta unidad reinante al interior de un colectivo general e inespecífico ("los historiadores de la cultura”) resulta al menos irónica, ya que dicho 
supuesto contrasta abiertamente con la recepción crítica, por parte de ese sector, de la hipótesis de lo inconsciente y la sexualidad, planteada por Freud en Die Traumdeutung (1900 [1899]) y Psychopathologie des Alltagslebens (1901).

Nuevamente en Tres ensayos de teoría sexual (1905), Freud sugiere que: "El tercer desenlace de una disposición constitucional anormal es posibilitado por el proceso de la "sublimación". En ella, a las excitaciones híperintensas que vienen de las diversas fuentes de la sexualidad se les procura drenaje y empleo en otros campos, de suerte que el resultado de la disposición en sí peligrosa es un incremento no desdeñable de la capacidad de rendimiento psíquico. Aquí ha de discernirse una de las fuentes de la actividad artística” (1905: 218). En este nivel predomina lo que MacIntyre (1958) denominó el modelo hidráulico: Freud habla de "drenaje", identifica a la sublimación como "fuente" de la actividad artística y concibe a la sublimación como un proceso de desviación de las fuerzas pulsiones. La sublimación, al sortear otros destinos pulsionales, despeja el camino para que la pulsión se exprese. En la medida en que desvía las fuerzas pulsionales sin intervenir o alterar su estructura más fundamental, le permite a la pulsión "desplegar libremente su quehacer al servicio del interés intelectual” (Freud, 1910: 75). Este modelo se repite en La moral sexual "cultural" y la nerviosidad moderna (1908), cuando dice: "La pulsión sexual [...] pone a disposición del trabajo cultural unos volúmenes de fuerza enormemente grande, y esto sin ninguna duda se debe a la peculiaridad, que ella presenta con particular relieve, de poder desplazar su meta sin sufrir un menoscabo esencial en cuanto a la intensidad. A esta facultad de permutar la meta sexual originaria por otra, ya no sexual, pero psíquicamente emparentada con ella, se le llama la facultad para la sublimación” (1908: 168). Es decir, la sublimación aparece como aquel proceso mediante el cual las fuerzas pulsionales son desviadas (abgelenkt) de sus metas (sexuales) originales y son dirigidas a metas socialmente elevadas, ya no sexuales. Esta definición se repite nuevamente en las Conferencias de introducción al psicoanálisis (1916-17) a propósito de la exigencia de sacrificio de satisfacción pulsional por parte de la cultura: "Entre las fuerzas pulsionales así empleadas, las pertenecientes a las mociones sexuales desempeñan un importante papel; en ese proceso son sublimadas, vale decir, desviadas de sus metas sexuales y dirigidas a otras, que se sitúan socialmente en un plano más elevado y ya no son sexuales" (1916-17: 20).

En El yo y el ello (1923), tres años después de la introducción de la pulsión de muerte en Más allá del principio de placer (1920), Freud retoma el asunto de la sublimación a propósito de la energía de desplazamiento, que en sí es indiferenciada y que puede ser agregada a una moción erótica o destructiva. Caracteriza a dicha energía como desexualizada ${ }^{12} \mathrm{y}$, por ello, la piensa como sublimada, "pues seguiría perseverando en el propósito principal del Eros, el de unir y ligar, en la medida en que sirve a la producción de aquella unicidad por la cual -o por la pugna hacia la cual- el yo se distingue” (Freud, 1923: 46). Por lo tanto, se trataría de un movimiento que, por el momento, se dirigiría hacia la meta del Eros, que es el de "complicar la vida mediante la reunión... para conservarla" (1923: 41). No obstante, aquel movimiento de inmediato tiene que ser complementado por la consideración que es difícil pensar

\footnotetext{
P. Ricoeur va a hacer notar en este punto que lo que en la primera tópica se trataba de desplazamiento de la meta de la sublimación ahora va a ser tratado como desexualización (Ricoeur 1965).
} 
a las pulsiones agresivas de modo independiente de las sexuales, ya que, por lo general, éstas se encuentran mezcladas. Por consiguiente, se hace necesario formular la pregunta por el destino pulsional de las pulsiones tanáticas: ¿La sublimación opera solamente sobre Eros o también actúa sobre Tánatos?

\section{DEL QUIASMA POSIBLE}

Si bien ni en la obra de Goethe ni de Freud aparecen teorías cabalmente formuladas sobre la sublimación, es decir, doctrinas definitivas o sistemas del pensamiento, al menos es posible rescatar ciertos fragmentos o desarrollos parciales que pueden ser identificados retrospectivamente como precursores y formulaciones preliminares del concepto en cuestión. Esto, más que una dificultad infranqueable o una imposibilidad, impresiona como una fortaleza y posibilidad, ya que el pensamiento de ambos, más allá de sus respectivas diferencias o pretensiones, puede ser leído como una serie - no necesariamente cronológica - de enunciados situados, preliminares y transitorios que no aspiran a configurarse como conocimiento dogmático o irrefutable. Es el caso de las incursiones goethianas en el arte, la música y la estética, pero también de la teoría freudiana de la seducción, la teoría del trauma, la teoría de las neurosis e incluso de la llamada metapsicología, para nombrar solamente a algunas. Se trata, en cada caso, de formulaciones regionales y contingentes que responden a problemas puntuales y precisos, inscritos en contextos históricos particulares tanto de la época como de la obra de ambos, acotados en cuanto a sus correspondientes contornos o recintos teóricos. La actualidad tanto de Goethe como de Freud consiste, por ende, justamente en su recusación decidida de toda práctica que aspire a convertirse en cosmovisión o visión-de-mundo, Weltanschauung, construcción intelectual capaz de responder, de modo inequívoco y unitario, a cualquier problema que se le plantee, apelando a una hipótesis suprema. El surgimiento del pensamiento de ambos se ve vinculado inexpugnablemente a una actitud polémica y crítica, un intento de superación de los modos de pensar establecidos y del pensamiento concreto existente. La apertura el desocultamiento del sentido que se vuelve posible a partir de estas relaciones elementales e inconclusas, en lugar de inducir a desechar el desafío de pensar el concepto de sublimación, confirma la ruptura y el quiebre con los modos asentados de pensar, introducidos por éste.

En efecto, resulta difícil pensar a la sublimación como una conversión cuasimágica, milagrosa, total, sin residuos ni pérdidas. Más bien, haciéndose cargo del carácter parcial e incompleto de las formulaciones revisadas, pareciera ser más productivo pensarla desde la imposibilidad y la resistencia, es decir, desde aquello que marca sus límites, tanto externos como internos y define sus fronteras. En el caso de Goethe, el siguiente pasaje, extraído del Torquato Tasso, puede servir como ilustración de lo anterior: "Sólo una cosa permanece: las lágrimas nos ha dado la naturaleza, / El grito de dolor cuando el hombre, al último, ya no (lo) soporta-" (Goethe 1790: 220, trad. nuestra). ${ }^{13}$ El guión, como ha subrayado Goebel (2009), a través del corte mudo que introduce en el espeso tejido significante de la escritura,

\footnotetext{
Nur eines bleibt: Die Träne hat uns die Natur verliehen,/ Den Schrei des Schmerzens, wenn der Mann zuletzt/ Es nicht mehr trägt-".
} 
marcaría el lugar de lo insoportable, lo indecible e irrepresentable, la frontera insalvable de la articulación lingüística. En efecto, como exclama Torcuato Tasso ante la interpelación de Antonio, frente a lo insufrible, lo inaguantable, solamente permanecen las lágrimas, que al hombre le han sido concedidas como medio o recurso de la expresión de su dolor y el grito. Ambos marcan una frontera desgarradora e insoportable, un momento liminar, cuando el ser humano ya no lo soporta (erträgt), cuando ya no es soportado (getragen) por el tejido socio-simbólico.

Es decir, por más arte con que opere la sublimación, por más que se empeñe en completar su tarea, en la medida en que expresa, de modo "puro", lo más propio de la pulsión, siempre permanecerá un resto insublimable. Persiste, más allá de toda posibilidad de desviación, la obstinada insistencia de lo que no se deja sublimar, resistiéndose a todo torcimiento sublimatorio. En contra de la posibilidad de una sublimación "total", sin restos ni restantes, tal como le sucedió a Freud en su inauguración de la vía regia hacia lo inconsciente, nos encontramos en su lugar con un punto compacto, espeso, impenetrable: "un lugar en el cual es insondable, un ombligo por el que se conecta con lo no conocido" (1900: 132, n. 18.) O sea, la sublimación, por más ideal que se pretenda, se topa, irremediablemente, con algo que resiste a ser sublimado: un punto, tenaz y renuente, en el cual se muestran y entremezclan "todas las significaciones de equivalencia, todas las condensaciones que [uno] pueda imaginar" (Lacan, 1983: 188.). Madeja de procesos primarios, lioso entrelazamiento de encadenamientos significantes, anudamiento, enlace o ligadura (Verknüpfung) imposible de disolver. Es en esta desgarradura del tejido del lenguaje donde se produce el (des)encuentro con lo Unerkannte, lo no-(re)conocido e innombrable, en torno al cual se umbilican las cadenas significantes que, ocultándolo, lo protegen para mantenerlo en su estatuto de causa del discurso.

El guión en Torcuato Tasso, de este modo, representa aquel topos inaccesible, que no representa una frontera provisoria, transitoria, sino que evoca "la noche más oscura”, lo desconocido impenetrable, no-simbolizado, que se sustrae a la capacidad sistematizadora del lenguaje. ${ }^{14}$ Suerte de omphalos, punto ciego, que escapa a los esfuerzos sublimatorios y que, justamente, a través de su sustraerse se constituye en su carácter de mancha o lugar vacío inherente al texto simbólico. Lejos de situarse en la más absoluta exterioridad del lenguaje, en un más allá transcendental, le pertenece íntimamente a lo Simbólico conformando su delimitación interna. Por lo tanto, la función de aquel residuo no-sublimable consiste precisamente en impedir que en el plano del lenguaje se produzca la identidad consigo mismo, es decir, que el orden simbólico "retorne a sí mismo" y que se cierre la hiancia constitutiva del lenguaje. Aquella discrepancia irreducible, ese resto imposible de decir, sería entonces lo que nos constituye como parlêtres y que, como consecuencia, nos permite y nos hace hablar. Tanto Goethe como Freud no solamente testimonian su des-encuentro con lo no-sublimable, sino que dejan entrever que su obra, en tanto práctica escritural, no sería pensable sin dicho choque e incluso constituye el testimonio dislocador del encuentro con lo eternamente innombrable.

14 Con esto, el ombligo presenta una asombrosa coincidencia con el ser de Heidegger, el que, como éste insiste en remarcar una y otra vez, no es que esté simplemente sustraído, retirado o privado (entzogen), sino que el ser no "es" otra cosa que su propio sustraerse. 


\section{OBRAS CITADAS}

Assoun, Paul-Laurent. 1996. Littérature et psychanalyse: Freud et la création littéraire. París: Ellipses.

Bachelard, Gaston. 1948. La formation de l'esprit scientifique. Paris: Vrin.

Becker, Aloys. 1972. "Arthur Schopenhauer-Sigmund Freud. Historische und charakterologische Grundlagen ihrer gemeinsamen Denkstrukturen”. JB 52: 114-156.

Bergstraesser, Arnold. 1950.” Goethe und unsere Zeit”. Monatshefte 42,2: 77-88.

Biedermann, Woldemar Frhr. von (ed.). 1910. Goethes Gespräche. Gesamtausgabe, Leipzig: F. W. v. Biedermann.

Blod, Gabriela. 2003. Lebensmärchen: Goethes Dichtung und Wahrheit als poetischer und poetologischer Text. Würzburg: Königshausen und Neuman.

Borek, Johanna. 2010. "Dem Original gegenüber treu und demütig”. Der Standard, disponible en http://derstandard.at/1271375930544/Interview-Dem-Original-gegenueber-treu-unddemuetig.

Braunstein, Néstor (ed.). 1975. Psicología: ciencia e ideología. México: Siglo XXI.

Clark, Ronald W. 1980. Freud: The Man and the Cause. New York: Random House.

Cohn, Jan y Miles, Thomas N. 1977. "The Sublime: In Alchemy, Aesthetics, Psicoanálisis". Modern Philology 74: 289-304.

De Berg, Hans. 2004. Freud's Theory and Its Use in Literary and Cultural Studies. Rochester, NY: Camden House.

Ernout, Alfred y Meillet, Antoine. 1979. Dictionnaire étymologique de la langue latine. Histoire des mots. 4a edición. Paris: Éditions Klincksieck.

Falzeder, Ernst. 2007. "Is there still an unknown Freud? A note on the publications of Freud's texts, and on unpublished documents". Psychoanalysis and History 9,2: 201-232.

Fichtner, Gerhard. 1989. "Freuds Briefe als historische Quelle". Psyche 43: 803-829.

Freud, Sigmund. 1897 [2003]. "Manuscrito N".Obras Completas, tomo I, Buenos Aires: Amorrortu.

1900 [2003]. "La interpretación de los sueños". Obras Completas, tomo IV-V, Buenos Aires: Amorrortu.

1901 [2003]. "Fragmentos de análisis de un caso de histeria". Obras Completas, tomo VII, Buenos Aires: Amorrortu.

1905 [2003]. "Tres ensayos de teoría sexual". Obras Completas, Vol. VII, Buenos Aires: Amorrortu, 2003.

1908 [2003]. "La moral sexual "cultural" y la nerviosidad moderna". Obras

Completas, Vol. IX, Buenos Aires: Amorrortu. 1909 [2003]. "Cinco conferencias sobre psicoanálisis". Obras Completas, Vol.

XI, Buenos Aires: Amorrortu.

. 1910 [2003]. "Un recuerdo infantil de Leonardo da Vinci". Obras Completas,

Vol. XI, Buenos Aires: Amorrortu.

1917 [2003]. "Un recuerdo de infancia en Poesía y verdad". Obras Completas,

Vol. XVII, Buenos Aires: Amorrortu.

Amorrortu.

1923 [2003]. "El yo y el ello". Obras Completas, Vol. XIX, Buenos Aires:

1925 [2003]. "Presentación autobiográfica". Obras Completas, Vol. XX, Buenos Aires: Amorrortu.

1930 [2003]. "El malestar en la cultura". Obras Completas, Vol. XXI, Buenos

Aires: Amorrortu.

1930 [2003]. "Premio Goethe". Obras Completas, Vol. XXI, Buenos Aires:

Amorrortu.

Gasser, Reinhard. 1997. Nietzsche und Freud. Berlin: De Gruyter. 
Gay, Peter. 1988. Freud; A life for our time. New York: W. W. Norton.

Gay, Volney P. 1992. Freud on Sublimation: Reconsiderations. Albany: State University of New York Press.

Goebel, Eckart. 2009. Jenseits des Unbehagens. “Sublimierung” von Goethe bis Lacan. Wien: transcript.

Goeppert, Sebastian y Goeppert, Herma C. 1981. Psychoanalyse interdisziplinär: Sprach- und Literaturwissenschaft. München: Fink.

Goethe, Johann Wolfgang von. 1790. Torquato Tasso. Ein Schauspiel. Leipzig: G. J. Göschen.

Goethe, Johann Wolfgang von. 1948. "Aus meinem Leben. Dichtung und Wahrheit". Goethes Werke. Hamburger Ausgabe in 14 Bänden, Tomo 9, Hamburg: Christian Wegner.

Habermas, Jürgen. 1968. Erkenntnis und Interesse. Frankfurt am Main: Suhrkamp.

Hacker, Frederick J. 1972. Sublimation Revisited. Int. J. Psycho-Anal 53: 219-223.

Jahoda, Maríe. 2002. Freud y los problemas de la psicología. México, D.F.: Coyoacán.

Jones, Ernest. 1953. Sigmund Freud: Life and Work. Vol 1: The Young Freud 1856-1900. London: Hogarth Press.

Jones, Ernest. 1955. Sigmund Freud: Life and Work. Vol 2: The Years of Maturity 1901-1919. London: Hogarth Press.

Jones, Ernest. 1957. Sigmund Freud: Life and Work. Vol 3: The Last Phase 1919-1939. London: Hogarth Press.

Jung, Carl G. 1977. Speaking, Interviews and Encounters. Princeton, NJ: Princeton University Press.

Lacan, Jacques. 1983. Seminario 2. El Yo en la Teoría de Freud y en la Técnica Psicoanalítica (1954-1955). Buenos Aires: Paidós.

Laplanche, Jean y Pontalis, Jean-Bertrand. 1967. Vocabulaire de la psychanalyse. Paris: PUF.

MacIntyre, Alasdair C. 1958. The Unconscious. London: Routledge.

Merleau-Ponty, Maurice. 1945. La Phénoménologie de la perception. Paris: Gallimard.

Mertens, Wofgang y Waldvogel, Bruno (eds.). 2000. Handbuch psychoanalytischer Grundbegriffe. Stuttgart: Kohlhammer.

Mommsen, Catarina. 1999. Goethe und unsere Zeit. Frankfurt a. M.: Suhrkamp.

Pechriggl, Alice. 2006. Chiasmen: antike Philosophie von Platon zu Sappho-von Sappho zu uns. Wien: Transcript.

Pfaller, Robert. 2009. "Die Sublimierung und die Schweinerei. Theoretischer Ort und kulturkritische Funktion eines psychoanalytischen Begriffs". Psyche 63,7: 621-650.

Ricoeur, Paul. 1965. De l'interprétation. Essai sur Sigmund Freud. Paris: Le Seuil.

Ricoeur, Paul. 1969. "La psychanalyse et le mouvement de la culture contemporaine". Le conflit des interprétations. Essais d'herméneutique. Paris: Seuil.

Sachs, Hanns. 1982. Freud. Meister und Freund. Frankfurt a. M./ Berlin/Wien: Ullstein.

Starobinski, Jean. 1970. La relation critique, l'œil vivant II. Paris: Gallimard.

Suarès, André. 1932. Goethe: le grand européen. Paris: E.P. Fréres.

Wischer, Erika. 1981. Geschichte der Literatur: Literatur und Gesellschaft der westlichen Welt. Berlin: Propyläen Verlag.

Zaretsky, Eli. 2006. Freuds Jahrhundert. Die Geschichte der Psychoanalyse. Wien: Zsolnay. 